\title{
Business Model Canvas to Create and Capture AI-enabled Public Value
}

\author{
Samar Fatima \\ QUT Business School, \\ Queensland University of Technology \\ samar.fatima@hdr.qut.edu.au \\ Christoph Buck \\ Centre for Future Enterprise, QUT Business School, \\ Queensland University of Technology \\ christoph.buck@qut.edu.au \\ Philipps-Universität Marburg \\ christoph.buck@wiwi.uni-marburg.de
}

\author{
Kevin C. Desouza \\ QUT Business School, \\ Queensland University of Technology \\ kevin.desouza@qut.edu.au \\ Erwin Fielt \\ School of Information Systems, \\ Queensland University of Technology \\ e.fielt@qut.edu.au
}

\begin{abstract}
The compatibility between the business model and AI-enabled value creation is paramount for the sustainability of organizations. The public sector lags the private sector in the race to AI readiness and adoption. Although the concept of the business model for the public sector has previously been discussed, we found a lack of evidence for the process of adaption of the business model as a value creation and capture tool from commercial motives to public value motives. This paper adapts the conventional business model canvas for the public sector as it pertains to the design and development of AI systems. Employing a designscience research approach, we postulate five design principles that public agencies must follow to design and deploy AI-enabled public services.
\end{abstract}

\section{Introduction}

Public agencies strive for improved public services and economic efficiency [9]. Interestingly, governments have realized the potential of AI for their services, such as the launch of strategic AI plans and million-dollar investments in AI projects [15]. However, public agencies lack a structured framework to harness the potential of AI for increasing public value [4]. While understanding the dynamics of AIenabled value creation and capture tools, we observed a lack of robust tools for public agencies. For example, the business model canvas (BMC) is a proven tool for fostering value creation that is popular among commercial entities. Due to the difference between the private and public sectors, tools designed with commercial motives remain unfruitful for public organizations. However, designing such tools is important for public agencies as well because, without outlining the practicalities of the value creation process using disruptive technologies, no organization can optimally benefit from them. In addition, technology has no inherent value, unless it is deployed according to an organization's unique needs. In order to gain an AI-enabled competitive advantage, the configuration of AI and value orientation must also coincide [7]. Given the importance of the BMC as a proven valuecreation and capture tool and the fundamental difference between the value orientation of public and private organizations, we decided to adapt the original template of BMC for public agencies to create value through AI-enabled public services. Thus, our research question is: "How can the business model canvas be adapted for public agencies as a value creation and capture tool for AI-enabled public services?"

\section{Artificial intelligence and public sector}

AI offers exciting potential for innovation in all government sectors and industries [11]. In the public sector, several facets of AI applications create value, such as knowledge management, process automation, virtual agents, predictive analytics, data visualization, identity analytics, robotics, digital assistants, security analytics, and threat intelligence. When governments use AI in public service design and delivery, it can improve the efficiency and quality of public services [41]. To strengthen AI-enabled public services, governments are investing in capacity development for $\mathrm{AI}$ - for instance, the release of national strategies by 34 countries to launch $\mathrm{AI}$ as a national priority and the 
inclusion of more than eleven public services to be transformed by AI [15]. Despite the need to investigate AI innovation in public services, little evidence is available about the readiness of public agencies to transform the structure of business models and optimally deploy AI. Business models of public agencies are often inflexible to innovation; the bureaucratic structure, resource scarcity, centralized decision-making, and lack of empowerment are some of the factors that hinder the process of innovation in public agencies [5]. Thus, any transformation such as AI application yields sub-optimal outcomes due to the incompatibility between the traditional business model and newly launched innovative technology [12]. The business model as a value-creation and capture tool plays a significant role in maximizing the value of AIdriven initiative in public services. Therefore, we emphasize the structural reforms in business models of public agencies to deliver AI-enabled services to the public.

\section{Business models}

A business model is a conceptual tool that defines the value logic of an organization. It outlines the set of objects, concepts, and their relationships to represent the value-creating and capturing mechanisms of a business. It describes the rationale for creating, delivering, and capturing value [32]. The role of business models in private sector innovation is widely discussed [7]. However, little is known about deploying new business models in public-sector organizations [29]. Moreover, existing literature on the BMs of public agencies focuses on one or two dimensions of it, such as the role of networks in value creation [29], stakeholders (for example, industry partners as stakeholders [28], or public engagement [33]). Little evidence has been found for all dimensions of BMs and the relevant actors of public agencies. In addition, we found instances of the myth that social sector organizations (government and NGOs) are not required to have a business model as they are not involved in any business. Any organization interested in articulating its value logic has a business model; the difference, however, lies in defining value orientation across organizations in the commercial and social sectors [22]. Therefore, we decided to identify the most appreciated value creation and capturing tool and adapt it according to the value orientation of public agencies. Osterwalder and Pigneur [31] presented the rationale for BMs and developed a visual inquiry tool to operationalize the abstraction of this high-level concept in identifiable terms and usable format. This tool is named the Business Model Canvas (BMC), and it is intended to describe, analyze, and design BMs.
Recently, the BMC has become the most widely adopted BM development tool. The original BMC is described in a combination of nine building blocks. The building blocks of BMC as defined by Osterwalder and Pigneur [31] are key partners, key resources, key activities, value propositions, customer segments, customer relationships, channels, cost structure, and revenue streams.

\section{Design science research methodology}

The importance of design science is widely recognized in information systems (IS) literature. IS research has focused on the application of design artifacts [3]. In information systems, the design science paradigm deals with innovation in the technical and non-technical dimensions of system design to maximize system output [18]. It also aims to create and evaluate design artifacts intended to solve real-world problems [34]. A design artifact can be defined as an artificially made object, model, instantiation, or process [17]. In this study, the BMC as a design artifact takes a holistic approach to support AI-enabled public value generation in public agencies. The methodology of this study is based on the Peffers [34] DSRM which has six steps - starting with the identification of a problem, defining the objectives of the solution, designing artifacts, demonstrating the solution, evaluating the effectiveness, and communicating the solution. In this study, the first three steps of Peffers [34] DSRM are used to identify a lack of value creation and capture tools in public agencies when AI-enabled public services are offered. BMC is a proven tool to create and capture value in commercial organizations and is here used for exaptation for public agencies. Innovation through exaptation is a widely adopted facet of public sector innovation [4]. The study is conducted using the first three steps of DSRM, namely problem identification, objectives of the solution, and initial design of the business model canvas. In future studies, the remaining elements of DSR ought to be employed. Figure 1 displays the DSR process for this study and highlights dotted shapes and arrows for work to be done in forthcoming research. The study does not design a new artifact; rather, it adapts the original BMC for public agencies and presents its initial design. The adaption process is guided by a set of design principles discussed in the next section.

\section{Design principles}

\subsection{Uniformity of BMC}


The use of technology to enhance public value while minimizing administrative burden is common at all levels and types of public agencies [35]. For instance, using conversational AI to make federal, state, and local services instantaneously available and saving staff time to engage in more complex tasks [2] is common nowadays. Public agencies are deploying chatbots as the first point of contact to provide instant response and understandable navigation instructions to citizens [25].

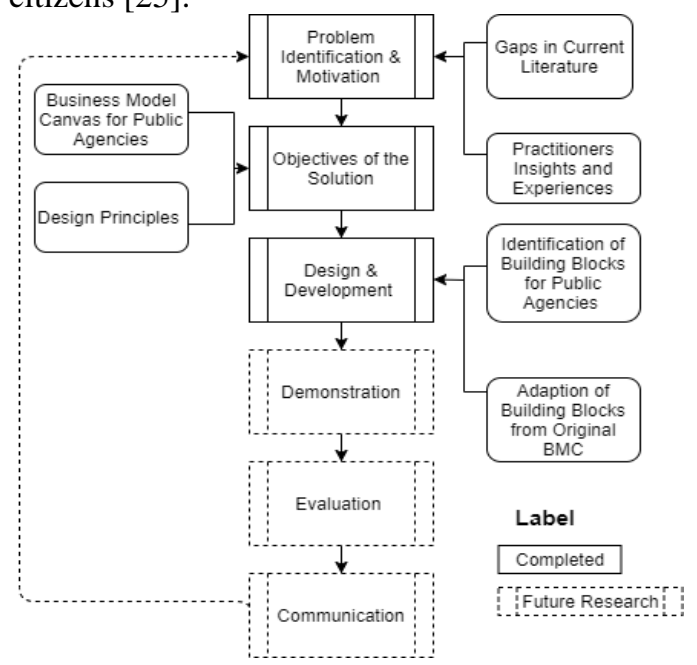

Figure 1. DSR Process

Regardless of the type of chatbot or the nature of service that it provides, one must consider the same set of key issues when designing, testing, and deploying them in the public sphere. Similarly, with other AI technologies being deployed in the public sector, we argue that, while the peculiarities of a given technology might be distinct, it is important to design a single $\mathrm{BMC}$ that is versatile and comprehensive enough to cover all relevant key components. By following the standardized design principles, the BMC of public agencies contributes to achieving economies of scale and facilitates the pooling of resources [10]. We suggest that the BMC of public agencies be generic enough to be applied to various levels and types of public agencies.

DP1: The BMC must be applicable to levels and types of public agencies.

\subsection{Citizen-centric BMC}

As guardians of public interest, public agencies place citizens at the core of their business [23]. The business models of public agencies must exhibit a citizen-centric approach to safeguard public value. Public agencies must ensure that AI solutions can serve different segments of the population in a fair and equitable manner. FarmChat, an audio-only and audioplus-text AI application, is being used in India to assist farmers with expert advice. Considering the literacy rate in India (74.04\%) [16], these chatbots are designed to speak "Hindi" as the most widely spoken Indian language. However, due to the lowest digital literacy rate in rural areas, farmers reported dissatisfaction with the user interface and variety of accents [20]. This case indicates that conversational agents could offer huge benefits for digitally literate users (AI offerings). However, to make the same gadget helpful for digitally illiterate or less knowledgeable users (AI user-specific affordance), the business model must be adjusted. By highlighting these cases, we argue for citizen centricity in the business models of public agencies. This principle prioritizes the public value originating from the designed use of AI rather than AI per se (AI adoption without adjustment to user needs is not useful) [14]. The model must exhibit that AI is deployed to enhance the quality of citizen service experience and identify AI as a tool to achieve the larger objective of public value maximization

DP2: The BMC must be citizen centric.

\subsection{Pilot testing and AI experimentation}

For the full-scale deployment of AI systems in public agencies, the core issues of data, technical, and organizational readiness must be addressed [11]. Before deployment, rigorous testing of the system to evaluate technical robustness is critical; failure to adhere to testing means that AI systems could be disastrous. For example, the AI-enabled Canadian government's payroll system Phoenix failed to make salary payments to public sector employees and cost a loss of $\$ 2$ billion through wrong and delayed payments. According to investigations, Phoenix could not handle the complexity of the federal payroll system as it had not undergone the required number of iterations to be deployed at a large scale. The Ottawa administration suggested pilot testing against the real complexity of the federal government's HR and pay needs of the new payroll system in Canada [6]. Failure of AI systems in public agencies evades public trust; therefore, pilot testing before deployment has high stakes [27]. The business model, as an outline of value creation and capture [31] in public agencies, must exhibit pilot testing of AI-enabled system deployment. The emergence of innovation labs (i-labs) in the public sector also indicates ongoing public sector innovation through disruptive technologies. Through experimentation with AI solutions, public agencies can innovatively redesign processes and services [38]. We argue for the inclusion of $\mathrm{AI}$ experimentation in the 
business model of public agencies to create and capture greater public value. The BMC of public agencies must detect and mitigate potential risks for AI deployment as well as the capacity to enable pilot experiments for the untapped potential of AI.

DP3: The BMC must account for pilot testing and $\mathrm{AI}$ experimentation.

\subsection{Accurate, fair, efficient, explainable, and accountable AI}

Various instances indicate that AI-enabled systems can go wrong; for instance, accidents caused by selfdriving cars [19], racist remarks by chatbots [39], and crash of autonomous systems in unanticipated situations [37]. Similarly, public agencies are no exception to the malfunctioning of AI systems. For instance, it was feared that the facial recognition tool used by the Metropolitan Police of London could exhibit racial bias among nonwhite individuals [40]. The impact of malfunctioning in AI-enabled public services can be detrimental to national sovereignty [8]. Biased outcomes of AI systems such as pro-publica's tendency to declare non-Caucasian individuals more likely to commit crimes in comparison with Caucasian individuals caused distress among society [21]. The occurrence of any such discriminatory outcome could sabotage the objective of public value. Owing to the opaqueness of the system's design and delivery, AIenabled systems lack transparency and accountability [13]. For example, in the case of facial recognition bias in London's Metropolitan's Police AI system, intervention during the design phase could detect the issue. In addition, diversity in a team of system designers could also minimize the probability of design bias [36]. The accuracy of the AI-enabled system is also subject to the availability of quality data and its secure storage [26]. The business model can depict transparency in the AI system to enforce explainability to some extent. However, although transparency can only inform the technical clarification of algorithms, it remains unable to logically explain why the system performed in the way that it did [24]. The explainability involves various steps in the process of design, development, and deployment of the AI system and paves the way for accountability.

DP4: The BMC must support in creating accurate, fair, efficient, explainable, and accountable AI-enabled services.

\subsection{Co-creation of public value}

A careful cost-benefit analysis of AI-enabled solutions is necessary before transforming the business model of public agencies. The cost-saving motive is desirable in the public sector because of budgetary controls and constraints [5]. The cost-benefit analysis must ensure that benefits exceed the costs. A viable measure to assess the potential of AI-enabled public services is to evaluate cost savings and public service quality improvement [1]. The engagement of key stakeholders (for example, citizens) not only reduces the costs of technology but also enhances citizen ownership in service design [30]. Therefore, we argue that the business model of public agencies must include the co-creation of AI-enabled public services to improve the economic viability of these initiatives. In addition, citizens can suggest novel solutions to public services, such as Challenge.gov, which solicits innovative ideas by conducting online contests. At a more advanced level, citizens as designers can develop solutions for problems in public services, such as citizens in New York City and California having developed mobile apps to solve the issue of public parking [30]. If the BMC includes citizen engagement for the co-creation of public services, economic viability and effectiveness can be significantly improved. The BMC of public agencies must ensure the economic viability of efficient solutions with AI technologies.

DP5: The BMC must facilitate co-creation with stakeholders.

\section{Building blocks of adapted BMC}

Based on the design principles, the building blocks of BMC for public agencies are adapted as shown in Table 1. Next, we present the building blocks of the adapted BMC for AI-enabled public services of public agencies adapted from the original $\mathrm{BMC}$ from an industry perspective.

\subsection{Key Stakeholders}

The first block comprises key stakeholders from the public sector perspective. These are (1) citizens, (2) public agencies, (3) industry partners, (4) AI experts, and (5) regulatory bodies. Citizens, as defined in (DP2), lead the group of stakeholders and suggest that $\mathrm{BMC}$ must function to maximize value for citizens. We define citizens as direct users of, or those that are indirectly impacted by, public services. The priority of citizens is suggested over that of other stakeholders and AI technologies. The second key stakeholder discussed is public agencies as governments operate as a network of public agencies that all pursue the same objective, i.e., the creation and maximization of public value. The pattern of interaction among public agencies must contribute to the overall objective. Since AI in public agencies is in its early stages of development, 
therefore, coordination across organizational boundaries is particularly important; for example, data exchange, exchange of AI expertise (especially in lowbudget projects), and economies of scale for AI procurement are some of the benefits that public agencies can take from each other. The third key stakeholder comprises industry partners. The undeniable lead of industry in AI advancements creates the dependence of public agencies on tech companies, SMEs, and startups for consulting, outsourcing, pilot testing, and experimentation (DP3 and DP4). Moreover, tech giants can also sponsor or fund AI experiments in the public sector because they have larger digital resources, while public agencies are rich in data availability. The quest for acquiring and retaining AI talent is getting fierce with the sophistication of AI technologies. Public agencies are at a disadvantage in this competition due to resource constraints and centralized policies. Reluctance to inflexible working hours and patterns also makes public agencies a less desirable place to work. Without acquiring and retaining experts in the field, public agencies seem to struggle in the development and sustainability of AI solutions. The BMC of public agencies, therefore, must also realize the criticality of experts in the field for the design and deployment of robust AI systems. Failure to maintain the required level of AI experts could significantly jeopardize the citizen-centric approach (DP2), pilot testing (DP3), and accuracy of the system (DP4). The last key stakeholder identified in this study is regulatory bodies. AI adoption in the public sector is in its infancy. The inherent opacity in AI systems creates susceptibility to the accuracy, fairness, and legality of systems. Moreover, several instances when AI systems resulted in unintended consequences also signify the importance of AI regularization in both the public and private sectors. To regulate AI, the active role of national and international bodies is increasing dailyfor example, that of EU guidelines for data sharing (GDPR) and OECD's AI Regulatory Framework. DP4 represents the idea of $\mathrm{AI}$ regulations and a core focus on accountability in AI.

\subsection{Key Activities}

Four key activities supported by design principles are (1) data accessibility, (2) data security, (3) system design and deployment, and (4) AI experimentation. The accessibility of quality data is critically important for AI system design. The major contributors to the accuracy of AI output are the data upon which algorithms act; therefore, data define the quality of system delivery to a larger extent. The second key activity is associated with securing the data. Data security refers to all measures taken to protect data and related analytics from any malicious activity, theft, or impermissible usage. It also includes breaching the privacy of data owners and any intention to use them for uninformed consent. The issues related to data security are found in (DP4). System design and deployment is the third key activity and is suggested by all design principles with a larger emphasis from (DP3 and DP4). System design and deployment handle key issues such as inadvertent bias in data and algorithms and also include technical and organizational capacity building and pilot testing before the deployment of systems [11]. Innovative ideas for AI experimentation are the fourth key activity to embark on for public agencies' competitive advantage of a large database. The experimentation not only brings avenues for improved quality and low-cost solutions (DP3) but also supports generating revenue by posing public agencies as innovation hubs to national and international research agencies.

\subsection{Key Resources}

Three key resources for the AI-enabled BMC of public agencies are identified as (1) data, (2) technical capacity, and (3) industry linkages. If AI is the rocket, data are the fuel. The best algorithms and AI could not work alone without data, which are a combination of internal and external sources and often not in the required format. The data component is strengthened by all the design principles of BMC; however, for accurate, fair, and efficient AI (DP3), data are regarded as the most important resource. The BMC must outline the challenges related to finding data sources and determining ownership. Technical capacity is another key resource that needs to be developed by public agencies. It consists of the required infrastructure for necessary IT applications and technical resources to undertake AI-enabled systems. AI system design and deployment demand transformation in the technical resources and skillsets of employees. Such a significant shift raises challenges for public agencies. The development of technical capacity could not work in isolation; for example, the IT and HR departments cannot work on their own. The BMC must therefore lay out the plan for capacity building for technical resources and AI workforce management. The third key resource is industry linkages. Most governments are not "AI-ready" and must depend on strong relationships with the technology industry. Therefore, it is very important for governments to have reliable industry linkages with large technology companies as well as AI-startups to develop effective contracts with industry partners and ensure safe AI solutions.

\subsection{Citizen Segments}


The building block of customer segments is adapted as citizen segments from the public sector perspective and supported by the citizen-centric business model (DP2). The citizen-centric approach emphasizes the segmentation of citizens according to various demographics such as age, gender, education level, income level, location, and digital literacy, with

Table 1. BMC Building Blocks

\begin{tabular}{|c|c|c|}
\hline Building Blocks & Industry & Al-enabled Public Services \\
\hline $\begin{array}{l}\text { Key Partners } \\
\text { The network of suppliers and partners that make } \\
\text { the business model work }\end{array}$ & $\begin{array}{cl}\text { Key Partners } \\
-\quad & \text { Non-competitors } \\
- & \text { Competitors } \\
- & \text { Joint ventures } \\
- & \text { Buyer-supplier relationships }\end{array}$ & $\begin{array}{cl}\text { Key Stakeholders } \\
- & \text { Citizens } \\
- & \text { Public Agencies } \\
- & \text { Industry Partners } \\
- & \text { Al Experts } \\
- & \text { Regulatory Bodies }\end{array}$ \\
\hline $\begin{array}{l}\text { Key Activities } \\
\text { The most important things a company must do to } \\
\text { make its business model work }\end{array}$ & $\begin{array}{cl}\text { Key } & \text { Activities } \\
- & \text { Production } \\
- & \text { Problem-solving } \\
- & \text { Platform }\end{array}$ & $\begin{array}{cl}\text { Key Activities } \\
-\quad & \text { Data Accessibility } \\
- & \text { Data Security } \\
- & \text { System Design and Deployment } \\
- & \text { Al Experimentation } \\
\end{array}$ \\
\hline $\begin{array}{l}\text { Key Resources } \\
\text { The most important assets required to make a } \\
\text { business model work }\end{array}$ & $\begin{array}{cl}\text { Key Resources } \\
- & \text { Physical } \\
- & \text { Intellectual } \\
- & \text { Human } \\
- & \text { Financial } \\
\end{array}$ & $\begin{array}{cc}\text { Key Resources } \\
- & \text { Data } \\
- & \text { Technical Capacity } \\
- & \text { Industry Linkages }\end{array}$ \\
\hline $\begin{array}{l}\text { Customer Segments } \\
\text { The different groups of people or organizations } \\
\text { an enterprise aims to reach and serve }\end{array}$ & $\begin{array}{cl}\text { Customer } & \text { Segments } \\
- & \text { Mass market } \\
- & \text { Niche Market } \\
- & \text { Segmented } \\
- & \text { Diversified } \\
- & \text { Multi-sided platforms }\end{array}$ & $\begin{array}{cl}\text { Citizen Segments } & \\
- & \text { Segmentation based on: } \\
\circ & \text { Age } \\
\circ & \text { Gender } \\
\circ & \text { Education } \\
\circ & \text { Income level } \\
\circ & \text { Location } \\
\circ & \text { Digital Literacy } \\
\end{array}$ \\
\hline $\begin{array}{l}\text { Customer Relationships } \\
\text { The types of relationships a company } \\
\text { establishes with specific Customer Segments }\end{array}$ & $\begin{array}{cl}\text { Customer Relationships } \\
- & \text { Dedicated personal } \\
& \text { assistance } \\
- & \text { Self Service } \\
- & \text { Automated service } \\
- & \text { Communities } \\
- & \text { Co-creation }\end{array}$ & $\begin{array}{cl}\text { Citizen Relationships } \\
- & \text { Information Access } \\
- & \text { Communication Channels } \\
- & \text { Citizen Profile Management } \\
- & \text { Personalized Services } \\
- & \text { Information Disclosure } \\
- & \text { Transparency } \\
- & \text { Trust }\end{array}$ \\
\hline $\begin{array}{l}\text { Value Proposition } \\
\text { The bundle of products and services that create } \\
\text { value for a specific Customer Segment }\end{array}$ & $\begin{array}{cl}\text { Value Proposition } \\
- & \text { Newness } \\
- & \text { Performance } \\
- & \text { Customization }\end{array}$ & $\begin{array}{cl}\text { Value Proposition } \\
- & \text { Accurate } \\
- & \text { Fair } \\
- & \text { Efficient } \\
- & \text { Explainable } \\
- & \text { Accountable }\end{array}$ \\
\hline $\begin{array}{l}\text { Channels } \\
\text { The network of how a company communicates } \\
\text { with and reaches its Customer Segments to } \\
\text { deliver a Value Proposition }\end{array}$ & $\begin{array}{cl}\text { Channels } & \\
- & \text { Awareness } \\
- & \text { Evaluation } \\
- & \text { Purchase } \\
- & \text { Delivery } \\
- & \text { After Sales } \\
\end{array}$ & $\begin{array}{cl}\text { Channels } & \\
- & \text { Public Agencies Network } \\
- & \text { Outsourcing Partners Network } \\
- & \text { Citizen Feedback Loop }\end{array}$ \\
\hline $\begin{array}{l}\text { Cost Structure } \\
\text { The Cost Structure describes all costs incurred } \\
\text { to operate a business model }\end{array}$ & $\begin{array}{cl}\text { Cost Structure } \\
- & \text { Cost driven } \\
- & \text { Value driven } \\
- & \text { Fixed costs } \\
- & \text { Variable costs } \\
- & \text { Economies of scale } \\
- & \text { Economies of scope }\end{array}$ & $\begin{array}{cl}\text { Economic Cost } \\
- & \text { Infrastructure Investments } \\
- & \text { Al Skills Building } \\
- & \text { Outsourced Services } \\
\text { Social Cost } \\
-\quad \text { Loss of Jobs } \\
-\quad \text { Digital Divide } \\
-\quad \text { Socioeconomic Disparity }\end{array}$ \\
\hline $\begin{array}{l}\text { Revenue Streams } \\
\text { It represents the cash a company generates } \\
\text { from each Customer Segment (costs must be } \\
\text { subtracted from revenues to create earnings) }\end{array}$ & $\begin{array}{cl}\text { Revenue } & \text { Streams } \\
- & \text { Asset sale } \\
- & \text { Usage fee } \\
- & \text { Subscription fee } \\
- & \text { Renting } \\
- & \text { Licensing }\end{array}$ & $\begin{array}{cl}\text { Economic Value } \\
- & \text { Service Fee } \\
- & \text { Taxes } \\
- & \text { Fines } \\
- & \text { Fees as Innovation Hub } \\
\text { Social Value } \\
-\quad \text { High Standard of Living } \\
-\quad \text { Physical and Mental Wellbeing } \\
-\quad \text { Sustainable use of Public } \\
& \text { Resources }\end{array}$ \\
\hline
\end{tabular}

the aim to offer personalized public services. These segments enable personalized service experience for different citizen segments. The BMC of public agencies, however, must acknowledge the 
socioeconomic disparities that could arise due to such segmentation. For example, citizens residing in big cities have access to advanced AI-enabled services (self-check-in at public hospitals) as compared to those in remote locations. To reduce such variations in the quality of services, BMC must contribute to building long-term sustainability for AI (for example, increasing digital literacy rate).

\subsection{Citizen Relationships}

This building block is also mostly emphasized by the second design principle, i.e., a citizen-centric approach. The component suggests that the relationship between an agency offering AI-enabled public services and citizens must be established through information access, channels of communication, citizen profile management, personalized services, transparency and trust. These components are described by a citizen-centric approach (DP2) and the co-creation of public value (DP5). The BMC must maintain a reasonable amount of information disclosure. Such disclosure and transparency would enhance citizen trust (DP4) and opportunities for the co-creation of services (DP5). Hassle-free communication channels (the network of chatbots), citizen profile management, and the automatic updating of citizen information also contribute to the efficiency of public services (DP4).

\subsection{Value Proposition}

The sixth building block for BMC of AI-enabled public services is termed "value proposition" and is (1) accurate, (2) fair, (3) efficient, (4) explainable, and (5) accountable. These five features are linked to the set of all five design principles. The first feature is accuracy. The AI-enabled public services are deployed with the expectation of an increase in the accuracy of services; the logical reasoning to adopt artificial intelligent machines is to augment human capabilities and achieve a higher level of accuracy. The BMC of public agencies must outline the features that contribute to enhanced accuracy - for example, data acquisition and cleaning, and a diverse workforce - to produce highly accurate results. The second feature concerns the fairness of AI-enabled public services. Despite the growing sophistication in AI, the incidence of unfair outcomes is still common (e.g., the wrongly accused minorities in productive recidivism). Fairness by design and fairness by political dynamics must be outlined in the business model. The explainability of AI-enabled public services is the fourth feature of the value proposition. AI systems are under criticism for the inherent opacity in system design, delivery, and interpretation. Incidents due to malfunctioning strengthen the opposition against the unreadability of AI output. The last feature of AI-enabled public services' value proposition is accountability in AIenabled public services to acquire the society's trust in the government, and it outlines the responsibility and answerability of any actions or decisions. The BMC of public agencies must involve accountability in AIenabled public services at two levels: (1) algorithmic accountability (the responsibility of data scientists and system designers to provide justification for potential violations) and (2) algorithmic justice (the redress mechanism for any harm or malfunctioning in system outcome).

\subsection{Channels}

The seventh building block of the public sector BMC is a network of public agencies to deliver AIenabled public services. It includes (1) public agencies network, (2) outsourcing partners network, and (3) citizens' feedback loop. Public agencies as key stakeholders (DP2) are important for multifaceted benefits such as resource sharing and data exchange. All public agencies operate on behalf of the government to create and maximize value for one client (citizens). The strong network among agencies facilitates the sharing of resources; for example, if citizens' data updated in one agency were updated among other network participants, it would increase the efficiency and reduce the time required for service offerings. Similarly, the same format data would also require less time and would be more accurate among all network participants. The outsourcing partners network involves industry partners for outsourcing high-tech technologies and relates with key stakeholders (DP2) and co-creation (DP5) of design principles. Partner networks involve high-tech companies, AI SMEs, and startups that could compensate agencies in lacked resources and expertise (DP5). The outsourcing of a partners' network must be reliable yet careful. The selection of reliable partners would save public agencies from delayed deliveries or poor-quality solutions; however, too much dependence on outsourcing would also cause a huge surge in the economic viability of AI solutions (DP4). The BMC, therefore, ensures a balance between in-house capacity building and outsourcing. The third important channel involves citizens' feedback about a service. Citizens' feedback loop refers to acquiring citizens' feedback as output about service delivery and utilizing that feedback as input to service design. The BMC can thus utilize citizens' feedback to deliver citizen-centric public services (DP2). 


\subsection{Economic Cost}

The eighth building block of our adapted BMC for the public agencies depicts a major shift in the design for the two different perspectives. In the public sector, costs are not only measured in economic parameters; rather, the social facet of costs is also considered. We have added an additional layer in the cost structure to obtain two categories: (1) economic cost and (2) social cost. Economic costs are associated with the financial viability of the AI system and thus supported by the efficiency of the system (DP4) and cost-saving through the co-creation of public values (DP5). The elements of economic cost are infrastructure investments, AI skill-building programs, and charges for outsourced AI services. While making a choice for AI systems, the agencies must consider the bigger picture by comparing the opportunity cost of $\mathrm{AI}$ in the longer run. A comprehensive cost-benefit analysis must outline the proposed opportunities and development costs. For example, data cleaning, algorithm fine-tuning, and pilot testing are associated with the decision of AI system design and deployment.

\subsection{Economic Value}

An additional layer is also added to the revenue stream of public agencies: (1) economic value and (2) social value. The logic for an additional layer lies in the difference in the value orientation of both private and public agencies. From the public sector perspective, economic value is a subsidiary component to the main objective of public value creation. The economic value category includes the service fee, taxes, fines, and fees as an innovation hub. This revenue, as working capital, is required to operate the agency. Economic value represents the stream of funds required for running public agencies' operations.

\subsection{Social Cost}

The second category of the cost associated with the use of $\mathrm{AI}$ in public services is a social cost that is not measurable, such as economic cost. The three elements of the social cost identified in the study are: (1) loss of jobs, (2) digital divide, and (3) socioeconomic disparity. An efficient system is likely to reduce the number of humans required to perform the tasks, so the loss of redundant jobs is an obvious outcome; however, the BMC of agencies can employ the human resource potential for the high-level creative tasks of AI. Due to personalized public services (advanced services for digitally literate citizens and vice versa), the chances of a digital divide and

\begin{tabular}{|c|c|c|c|c|}
\hline \multicolumn{2}{|c|}{ Social Cost } & \multicolumn{3}{|c|}{ Social Value } \\
\hline \multirow{2}{*}{ 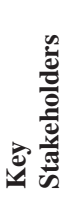 } & Key Activities & \multirow{2}{*}{ 总 } & $\begin{array}{l}\text { Citizen } \\
\text { Relationships }\end{array}$ & \multirow[b]{2}{*}{ 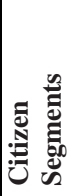 } \\
\hline & Key Resources & & Channels & \\
\hline \multicolumn{2}{|c|}{ Economic Cost } & \multicolumn{3}{|c|}{ Economic Value } \\
\hline
\end{tabular}

socioeconomic disparity among various social classes are also likely to emerge. If social cost elements are not addressed in BMC, they could jeopardize the effectiveness of design principles and ultimate objective of public value maximization.

\subsection{Social Value}

Social value, on the other hand, includes AIenabled public services' contribution toward an improved standard of living, the physical and mental well-being of citizens, and the sustainable use of public resources (e.g., natural resources and public funds). When deployed from public agencies' platforms; AI capabilities offer solutions to larger societal challenges. For example, AI-enabled healthcare services could improve the well-being of the public at large and offer quality care solutions for all citizens. The social value of AI is also supposed to protect human rights through the effective use of natural and public resources. It also safeguards a larger interest in human dignity by offering ethical, fair, and responsible public values.

\section{Discussion}

This paper adapts the conventional BMC for the public sector as it pertains to the design and development of AI systems. By following a DSRM approach, we postulate five DPs that public agencies must follow to design and deploy AI-enabled public services. Unlike commercial motives, the adapted $\mathrm{BMC}$ for the public sector indicates redefined building blocks in a rearranged order (see Figure 2). The adapted building blocks of BMC are shown in Table 1. The adapted BMC template presents a total of eleven building blocks, with social cost and social value placed at the upfront of the template. The remaining building blocks are key stakeholders, key resources, key activities, citizen segments, citizen relationships, value propositions, channels, economic cost, and economic value. Despite outlining the innumerable benefits that $\mathrm{AI}$ has to offer through public services with a prominent value creation and capture tool (BMC), public agencies need to consider the impact of AI-enabled services on the overall model of society. 
Public agencies must make a clear distinction to evaluate whether the expected benefits of AI-enabled public services (social value) could outweigh its costs (social cost).

\section{Conclusion and future research}

The study effectively adapted the original BMC for public agencies. The adaption process shows the addition of two building blocks, that is, social cost and social value. It also renames three building blocks of the original BMC: key partners as key stakeholders, customer segments as citizen segments, and customer relationships as citizen relationships. We outline a set of design principles to be followed by public agencies to determine value from technological solutions while prioritizing a citizen-first approach. The next step in our project is to continue to refine the building blocks of the canvas; next, we will deploy the canvas for use and test it with public agencies. This feedback will be essential for improvements. Despite a preliminary effort to expatiate BMC for public agencies for AIenabled public value, this study created our first pilot version of BMC We aspire to develop a solid design tool/business model canvas by following the practice of iterations in DSR. In our forthcoming research, we intend to create and evaluate links among various building blocks and consider deploying empirical testing using case studies or interviews.

\section{References}

[1] Agarwal, P.K., "Public Administration Challenges in the World of AI and Bots", Public Administration Review 78(6), 2018, pp. 917-921.

[2] Androutsopoulou, A., N. Karacapilidis, E. Loukis, and Y. Charalabidis, "Transforming the communication between citizens and government through AI-guided chatbots", Government Information Quarterly 36(2), 2019, pp. 358367.

[3] Benbasat, I., and R.W. Zmud, "Empirical Research in Information Systems: The Practice of Relevance", MIS Quarterly 23(1), 1999, pp. 3-16.

[4] Berryhill, J., K. Kok Heang, R. Clogher, and K. McBride, Hello, World: Artificial intelligence and its use in the public sector, Observatory of Public Service Innovation OECD, 2019.

[5] Bozeman, B., and S. Bretschneider, "Public Management Information Systems: Theory and Prescription", Public Administration Review 46, 1986, pp. 475-487.

[6] Charette, R.N., "Canadian Government's Phoenix Pay System an 'Incomprehensible Failure' - IEEE Spectrum”,
IEEE Spectrum: Technology, Engineering, and Science News, 2018.

[7] Chesbrough, H., "Business Model Innovation: Opportunities and Barriers", Long Range Planning 43(2), 2010, pp. 354-363.

[8] Chipeva, P., F. Cruz-Jesus, T. Oliveira, and Z. Irani, "Digital divide at individual level: Evidence for Eastern and Western European countries", Government Information Quarterly 35(3), 2018, pp. 460-479.

[9] Cole, R.W., "The Public Sector: The Conflict Between Accountability and Efficiency", Australian Journal of Public Administration 47(3), 1988, pp. 223-232.

[10] Cuijpers, M., H. Guenter, and K. Hussinger, "Costs and benefits of inter-departmental innovation collaboration", Research Policy 40(4), 2011, pp. 565-575.

[11] Desouza, K.C., G.S. Dawson, and D. Chenok, "Designing, developing, and deploying artificial intelligence systems: Lessons from and for the public sector", Business Horizons 63(2), 2020, pp. 205-213.

[12] Doganova, L., and M. Eyquem-Renault, "What do business models do?: Innovation devices in technology entrepreneurship", Research Policy 38(10), 2009, pp. 15591570 .

[13] Douglas, S., and A. Meijer, "Transparency and Public Value-Analyzing the Transparency Practices and Value Creation of Public Utilities", International Journal of Public Administration 39(12), 2016, pp. 940-951.

[14] Faraj, S., and B. Azad, "The Materiality of Technology: An Affordance Perspective”, In P.M. Leonardi, B.A. Nardi and J. Kallinikos, eds., Materiality and Organizing. Oxford University Press, 2012, 237-258.

[15] Fatima, S., K.C. Desouza, and G.S. Dawson, "National strategic artificial intelligence plans: A multi-dimensional analysis", Economic Analysis and Policy 67, 2020, pp. 178194.

[16] Gill, P., “'Technology bacha le' is not an option for everyone in India", Business Insider, 2020. https://www.businessinsider.in/tech/news/technology-isonly-saving-few-jobs-digital-divide-highlighted-byproblems-of-migrant-workers/articleshow/76316534.cms

[17] Gregor, S., and A.R. Hevner, "Positioning and Presenting Design Science Research for Maximum Impact", MIS Quarterly 37(2), 2013, pp. 337-A6.

[18] Hevner, A.R., S.T. March, J. Park, and S. Ram, "Design Science in Information Systems Research", MIS Quarterly 28(1), 2004, pp. 75-105. 
[19] Higgins, T., "How the Uber Self-Driving Car Could Have Missed Seeing the Pedestrian", Wall Street Journal, 2018. https://www.wsj.com/articles/how-the-uber-robot-carcould-have-missed-seeing-the-pedestrian-1521735245

[20] Jain, M., P. Kumar, I. Bhansali, Q.V. Liao, K. Truong, and S. Patel, "FarmChat: A Conversational Agent to Answer Farmer Queries", Proceedings of the ACM on Interactive, Mobile, Wearable and Ubiquitous Technologies 2(4), 2018, pp. 170:1-170:22.

[21] Julia Angwin, J.L., "Machine Bias”, ProPublica, 2016. https://www.propublica.org/article/machine-bias-riskassessments-in-criminal-sentencing

[22] Kaplan, S., "Business Models Aren't Just For Business”, Harvard Business Review, 2011. https://hbr.org/2011/04/business-models-arent-just-for

[23] King, S., and S. Cotterill, "Transformational Government? The role of information technology in delivering citizen-centric local public services", Local Government Studies 33(3), 2007, pp. 333-354.

[24] de Laat, P.B., and this link will open in a new window Link to external site, "Algorithmic Decision-Making Based on Machine Learning from Big Data: Can Transparency Restore Accountability?", Philosophy \& Technology; Dordrecht 31(4), 2018, pp. 525.

[25] Leon, J.P. de, "How it works: Know your Dewa bill, ask Rammas the 'chatbot", UAE, 2017. https://gulfnews.com/uae/government/how-it-works-knowyour-dewa-bill-ask-rammas-the-chatbot-1.2103426

[26] Mac Namee, B., P. Cunningham, S. Byrne, and O.I. Corrigan, "The problem of bias in training data in regression problems in medical decision support", Artificial Intelligence in Medicine 24(1), 2002, pp. 51-70.

[27] Margetts, H., and C. Dorobantu, "Rethink government with AI”, Nature 568(7751), 2019, pp. 163-165.

[28] Micheli, P., M. Schoeman, D. Baxter, and K. Goffin, "New Business Models for Public-Sector Innovation: Successful Technological Innovation for Government", Research-Technology Management 55(5), 2012, pp. 51-57.

[29] Moore, M., and J. Hartley, "Innovations in governance", Public Management Review 10(1), 2008, pp. 3-20.

[30] Nambisan, S., and P. Nambisan, "Engaging Citizens in Co-Creation in Public Services", IBM Center for The Business of Government, 2013, pp. 52.

[31] Osterwalder, A., and Y. Pigneur, "Business Model Generation: A Handbook for Visionaries, Game Changers, and Challengers | Wiley", Wiley.com, 2010.
[32] Osterwalder, A., Y. Pigneur, and C.L. Tucci, "Clarifying Business Models: Origins, Present, and Future of the Concept", Communications of the Association for Information Systems 16, 2005.

[33] Panagiotopoulos, P., M.M. Al-Debei, G. Fitzgerald, and T. Elliman, "A business model perspective for ICTs in public engagement", Government Information Quarterly 29(2), 2012, pp. 192-202.

[34] Peffers, K., T. Tuunanen, M.A. Rothenberger, and S. Chatterjee, "A Design Science Research Methodology for Information Systems Research", Journal of Management Information Systems 24(3), 2007, pp. 45-77.

[35] Reis, J., P.E. Santo, and N. Melão, "Artificial Intelligence in Government Services: A Systematic Literature Review", In Á. Rocha, H. Adeli, L.P. Reis and S. Costanzo, eds., New Knowledge in Information Systems and Technologies. Springer International Publishing, Cham, 2019, 241-252.

[36] Saxena, A., "Workforce Diversity: A Key to Improve Productivity", Procedia Economics and Finance 11, 2014, pp. 76-85.

[37] Taylor, J., “'Incompetence attack': MyGov website did not crash because of DDoS cyber attack, as Stuart Robert claimed", The 2020. https://www.theguardian.com/australianews/2020/mar/23/incompetence-attack-mygov-websitedid-not-crash-because-of-ddos-cyber-assault-as-stuartrobert-claimed

[38] Tõnurist, P., R. Kattel, and V. Lember, "Innovation labs in the public sector: what they are and what they do?", Public Management Review 19(10), 2017, pp. 1455-1479.

[39] Vincent, J., "Twitter taught Microsoft's friendly AI chatbot to be a racist asshole in less than a day", The Verge, 2016. https://www.theverge.com/2016/3/24/11297050/taymicrosoft-chatbot-racist

[40] Williams, R., "Met Police's facial recognition tech could fuel minority discrimination", inews.co.uk, 2020. https://inews.co.uk/news/technology/metropolitan-policelondon-analysis-facial-recognition-technology-389748

[41] Wirtz, B.W., J.C. Weyerer, and C. Geyer, “Artificial Intelligence and the Public Sector-Applications and Challenges", International Journal of Public Administration 42(7), 2019, pp. 596-615. 